\section{Opening the black box of mixed-metal TMP metallating reagents: direct cadmation or lithium-cadmium transmetallation? $\dagger$}

\author{
David R. Armstrong, Alan R. Kennedy, Robert E. Mulvey, ${ }^{*}$ John A. Parkinson and Stuart D. Robertson*
}

Received 30th March 2012, Accepted 5th July 2012

DOI: 10.1039/c2sc20392h

\begin{abstract}
Designed to remove some of the mystery surrounding mixed-metal TMP $(2,2,6,6-$ tetramethylpiperidide) metallating reagents, this study examines in detail "LiCd(TMP) $)_{3}$ " in its own right. Previously established as an excellent "cadmating" ( $\mathrm{Cd}-\mathrm{H}$ exchange) reagent towards a wide variety of aromatic substrates, " $\mathrm{LiCd}(\mathrm{TMP})_{3}$ " has been investigated by ${ }^{1} \mathrm{H},{ }^{13} \mathrm{C}$ and ${ }^{113} \mathrm{Cd} \mathrm{NMR}$ studies as well as by DOSY NMR spectroscopy. This evidence puts a question mark against its ate formulation implying it exists in THF solution as two independent homometallic amides. Exploring the reactivity of " $\mathrm{LiCd}(\mathrm{TMP})_{3}$ " with anisole as a test substrate, both experimentally by NMR studies and theoretically by DFT studies suggests a two-step lithiation/transmetallation process in which the initially formed ortho-lithiated species undergoes a reaction with $\mathrm{Cd}(\mathrm{TMP})_{2}$ to form new $\mathrm{Cd}-\mathrm{C}$ and $\mathrm{Li}-\mathrm{N}$ bonds. For completeness, the homometallic cadmium component $\mathrm{Cd}(\mathrm{TMP})_{2}$ has been comprehensively characterised for the first time including a crystal structure determination revealing a near-linear $\mathrm{N}-\mathrm{Cd}-\mathrm{N}$ arrangement.
\end{abstract}

\section{Introduction}

Chemists often choose metallation as an entry point on the road to constructing compounds. ${ }^{1}$ As far as synthetic manipulation is concerned, "no entry signs" are commonplace with inert $\mathrm{C}-\mathrm{H}$ bonds, but converting them to reactive C-metal bonds (metallation) opens up a highway of bond forming opportunities. Conventional practice has been to react a metallating agent with a substrate to generate a metallated intermediate, which can then be functionalised by reaction with an electrophile (Fig. 1a). Often the contents of the intermediate "black box" are invisible to the synthetic practitioner.

a)

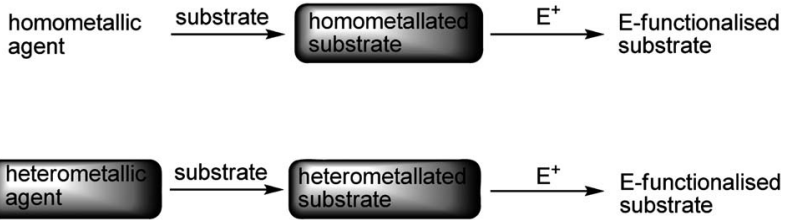

Fig. 1 Synthetic metallation routes for functionalising organic substrates.

WestCHEM, Department of Pure and Applied Chemistry, University of Strathclyde, Glasgow, G1 1XL,UK.E-mail:r.e.mulvey@strath.ac.uk $\uparrow$ Electronic supplementary information (ESI) available: Full experimental and theoretical details and selected NMR spectra. CCDC 874340. For ESI and crystallographic data in CIF or other electronic format see DOI: $10.1039 / \mathrm{c} 2 \mathrm{sc} 20392 \mathrm{~h}$
Historically, homometallic metallating agents have generally been employed due to their exceptional reactivity, commercial availability and general ease of handling. Such reagents often display drawbacks however; for example when hard, polar alkali-metal reagents such as alkyllithium or lithium amides are used, their high reactivity often necessitates utilisation at subambient temperatures while regioselectivity problems and undesirable side reactions with sensitive functional groups are frequently encountered. ${ }^{2}$ Opposing traits are often seen when using softer, more covalently bonded metal reagents such as those of magnesium ${ }^{3}$ or zinc, ${ }^{4}$ that is they can operate with the desired regioselectivity yet have a significantly diminished reactivity. Recently, advances have been pursued whereby two metals with opposing reactivities are combined within a single organometallic reagent which consequently can seemingly display the advantageous properties of its constituent parts, namely the reactivity of the hard alkali-metal coupled with the selectivity and better functional group tolerance of the secondary soft metal. ${ }^{5}$ Indeed not only can these heterobimetallic reagents execute soft metal superbasicity (through magnesium or zinc) superior to that of homometallic reagents, they can also display unique reactivities and selectivities including multi-deprotonation of a single substrate or meta oriented aromatic deprotonation.

Probably the most studied heterometallic complexes within this context have been alkali-metal magnesiates ${ }^{5 a, 6}$ zincates $^{5 a, 6}$ and aluminates, ${ }^{5 a, 7}$ although other combinations such as manganates, ${ }^{8}$ ferrates, ${ }^{9}$ cobaltates ${ }^{10}$ and cuprates ${ }^{11}$ have also received attention. Structural studies of important metallated intermediates from such reactions have revealed that it is the 
conventionally less reactive soft metal which occupies the site formerly held by hydrogen, although clearly the presence of the alkali-metal component is paramount since the polyvalent metal cannot typically execute the same transformation single-handedly. This alkali-metal influence was reflected in the coining of the phrase 'alkali-metal mediated metallation'.

As a consequence of the greater number of components (metals, anions) present and the multiple possible interplays between them, reaction solutions of heterometallic reagents should give rise to intrinsically more complex chemistry than that of their homometallic counterparts. If, as is common practice, metallation reactions are performed in situ in solution, the practitioner can be blind to the nature of the heterometallic reagent as well as to that of the metallated substrate intermediates (Fig. 1b). Visibility of the heterometallic reagent itself and its metallated substrates can help unravel this complexity and build up a more complete picture of the chemistry at work.

In that connection, we have recently become attracted to the mixed lithium-cadmium tris(2,2,6,6-tetramethylpiperidide) reagent formulated as " $\mathrm{LiCd}(\mathrm{TMP})_{3}$ " (1). Homoleptic lithium cadmates can trace their roots in organic functionalization back to the Wittig era, with soft cadmium outperforming its lighter sibling zinc in the metallation reaction of the organic substrate fluorene. ${ }^{12}$ Introduced by Uchiyama, Mongin et al. through an excellent series of papers, ${ }^{13} \mathbf{1}$ has been shown to operate as a highly efficient base for a number of substrates (see Fig. 2 for selected examples involving a benzothiazole, a benzamide and a pyrazine). However, little is currently known about the exact constitution of the base $\mathbf{1}$, with only indirect evidence in the form of DFT calculations ${ }^{13 a, 13 b}$ and $a{ }^{13} \mathrm{C}$ NMR spectrum being offered thus far. ${ }^{13 a}$ A particularly appealing facet of this chemistry is the NMR activity of the subordinate metal cadmium which has the potential to shed light on this, and by inference on other heterometallic 'ate' formulations. So as to gain a deeper understanding of the modus operandi of this interesting reagent, we have carried out an in depth study of $\mathbf{1}$ in its own right and also of the key intermediates involved in the blurred path described in Fig. 1b, and present our surprising findings herein.<smiles>c1ccc2scnc2c1</smiles>
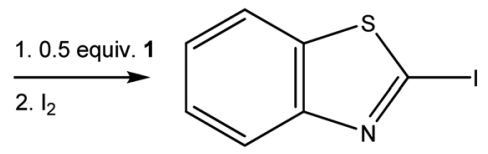

$(97 \%)$<smiles>CCOC(=O)c1ccccc1</smiles><smiles>CCOC(=O)c1ccccc1I</smiles><smiles>c1cncnc1</smiles><smiles>CCCCCCS(=O)(=O)O</smiles>

Fig. 2 Selected examples of cadmation reactions employing 1.

\section{Results and discussion}

The synthetic protocol developed by Uchiyama and Mongin to prepare the base $\mathbf{1}$ is summarized in eqn (1). It appears to be a straightforward transmetallation reaction achieved with a stoichiometry favouring the formation of an 'ate' complex.

$$
\begin{array}{r}
\mathrm{CdCl}_{2} \cdot \mathrm{TMEDA}+3 \mathrm{Li}(\mathrm{TMP}) \stackrel{\mathrm{THF}}{\longrightarrow} \mathrm{LiCd}(\mathrm{TMP})_{3}+2 \mathrm{LiCl} \\
+\mathrm{TMEDA}
\end{array}
$$

Previously this reaction was probed by DFT calculations (at the B3-LYP level) which computed that 1 was energetically feasible $\left(\Delta E=-1.0 \mathrm{kcal} \mathrm{mol}^{-1}\right)$ with respect to homometallic TMP species. These calculations did not take into account the influence of Lewis donors despite experimental evidence suggesting that they will coordinate to the alkali-metal in complexes of general type $\left[\mathrm{AM}(\mu \text {-anion })_{2} \mathrm{M}^{x}(\text { anion })_{x-1}\right](\mathrm{AM}=$ alkalimetal, $\mathrm{M}=$ polyvalent metal). We note that two coordinate TMP-Li-TMP fragments are precedented ${ }^{14}$ but the experimentally determined $\mathrm{N}-\mathrm{Li}-\mathrm{N}$ angle falls in the range 132.5(4)-178.2 $(2)^{\circ}$, significantly greater than that in the calculated structure of $\mathbf{1}$ $\left(119.2^{\circ}\right)$.

Consequently, we commenced our studies by calculating the energetics of the formation of $\mathbf{1}$ as a THF solvated species from the homometallic TMP species [LiTMP $\cdot \mathrm{THF}]_{2}{ }^{15}$ and $\mathrm{Cd}(\mathrm{TMP})_{2}$ as depicted in Scheme 1 (for full theoretical details of complex 1. THF see ESI $\dagger$ ). Such a calculation suggested that the overall reaction is approximately thermoneutral.

Synthetically, we commenced by examining whether $\mathrm{CdCl}_{2}$ can indeed undergo a transmetallation with Li(TMP) under the conditions used by Uchiyama, Mongin and co-workers (ambient temperature in THF) since a previously reported synthetic protocol required an overnight reflux of these materials (albeit in non-polar hexane solution). ${ }^{16}$ After one hour of stirring an aliquot was withdrawn and examined by ${ }^{1} \mathrm{H}$ NMR spectroscopy. This revealed only a trio of resonances consistent with a TMP anion but inconsistent with either previously published chemical shift values of $\mathrm{Cd}(\mathrm{TMP})_{2}$ (2) or Li(TMP) (vide infra). The bulk solvent was removed in vacuo, hexane added and the mixture was filtered. Upon removal of hexane and cooling a waxy yellow solid remained. Vacuum sublimation of this material yielded X-ray quality crystals which were shown by single crystal diffraction to actually be solvent-free $\mathrm{Cd}(\mathrm{TMP})_{2}$ (Fig. 3), which like its lighter zinc congener, ${ }^{17}$ is monomeric and represents a rare example of a monomeric cadmium bis(amide) to be structurally characterized in the solid state. ${ }^{\mathbf{1 8}}$

The previously reported ${ }^{1} \mathrm{H}$ NMR spectrum of 2 in $\mathrm{C}_{6} \mathrm{D}_{6}$ only specified the methyl singlet (found at $0.80 \mathrm{ppm} ;{ }^{16}$ whereas our spectrum shows this resonance at $1.25 \mathrm{ppm}$ ). In our experience of

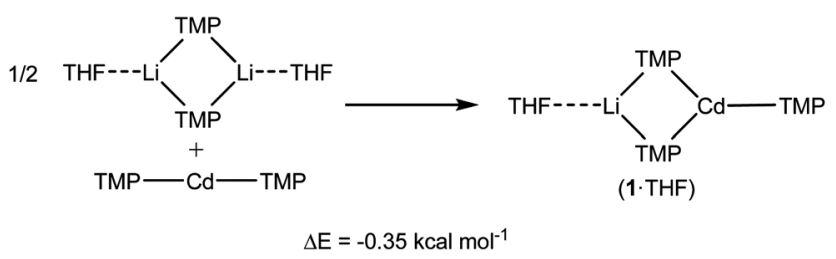

Scheme 1 Co-complexation synthesis of heterometallic 1·THF from homometallic reagents. 


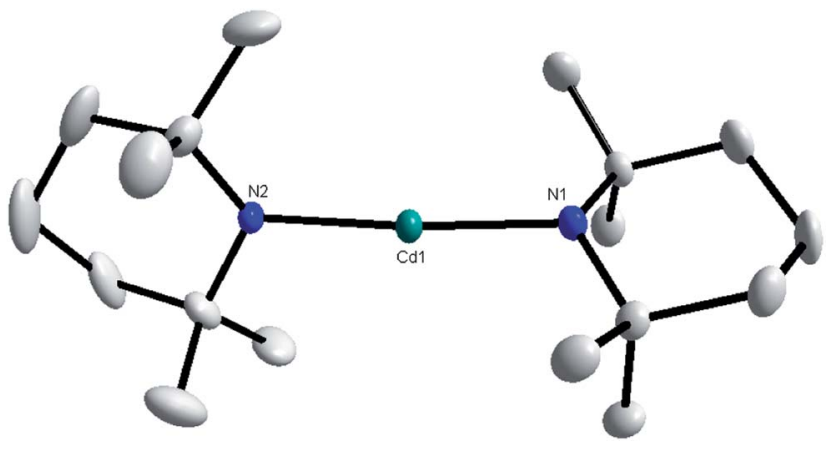

Fig. 3 Molecular structure of 2 with thermal ellipsoids at $50 \%$ probability and hydrogen atoms omitted for clarity. Cd1-N1 2.024(2) A, Cd1-

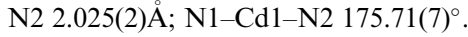

metal-TMP chemistry these methyl hydrogens are invariably deshielded with respect to parent $\mathrm{TMP}(\mathrm{H})$ (1.06 ppm) upon metallation and thus the new values reported herein are likely to be reliable. Despite this disparity in the ${ }^{1} \mathrm{H}$ NMR methyl resonances, our sample gave near identical ${ }^{13} \mathrm{C}$ and ${ }^{113} \mathrm{Cd} \mathrm{NMR}$ spectra to those previously reported by Fisher and Alyea. ${ }^{16 b}$ Also present in the ${ }^{13} \mathrm{C}$ NMR spectrum are ${ }^{113} \mathrm{Cd}$ satellites around the resonance corresponding to the $\beta$ carbon atom $\left({ }^{3} J_{\mathrm{Cd}-\mathrm{C}}=38 \mathrm{~Hz}\right)$. However, there are no ${ }^{3} J_{\mathrm{Cd}-\mathrm{C}}$ satellites around the more intense methyl resonance. This can be explained in general terms by the Karplus equation, ${ }^{19}$ which dictates that vicinal coupling is maximised when the torsion angle is closest to 0 or $180^{\circ}$ (average $\mathrm{Cd}-\mathrm{N}-\mathrm{C}_{\alpha}-\mathrm{C}_{\beta}=162.5^{\circ}$ in 2 and has little freedom to move in solution due to ring constraint) and minimised when such an angle is closer to $90^{\circ}$ (average $\mathrm{Cd}-\mathrm{N}-\mathrm{C}_{\alpha}-\mathrm{C}_{\mathrm{Me}}=45.9$ and $73.2^{\circ}$ for either side of the ring respectively, although these will have more flexibility in solution to move towards $90^{\circ}$ ).

With respect to the molecular structure, the $\mathrm{Cd}-\mathrm{N}$ bond lengths in $\mathbf{2}$ [2.024(2) and 2.025(2) $\AA$ ], are noticeably shorter than Kays previously reported bis-amido cadmium complex [2.107(4) and $2.117(4) \AA]^{18}$ and also than those previously calculated in the aforementioned DFT model $\left[\mathrm{Cd}-\mathrm{N}\right.$ in $\mathbf{2}_{\text {calc. }}=2.10 \AA$ ] while the $\mathrm{N}-\mathrm{Cd}-\mathrm{N}$ bond angle $\left[175.71(7)^{\circ}\right]$ is modestly closer to linearity than the calculated value $\left(173.6^{\circ}\right) .{ }^{13 b}$ The shorter $\mathrm{Cd}-\mathrm{N}$ bonds (with respect to the calculated model) brings the methyl limbs into close proximity to the group 12 metal and this steric shielding may explain why the metal centre in $\mathrm{Cd}(\mathrm{TMP})_{2}$ is seemingly unwilling to accept most neutral Lewis donating ligands (vide infra).

In an attempt to prepare and characterise a three coordinate bis-TMP cadmium centre we studied $\mathbf{2}$ in the presence of a variety of neutral Lewis donors via ${ }^{1} \mathrm{H}$ NMR spectroscopy. A selection of common mono- and multi-dentate neutral ligands bearing both hard and soft donor atoms were selected for this task. Specifically, THF, TMEDA $\left(N, N, N^{\prime}, N^{\prime}\right.$-tetramethylethylenediamine), PMDETA $\left(N, N, N^{\prime}, N^{\prime \prime}, N^{\prime \prime}\right.$-pentamethyldiethylenetriamine), $\mathrm{Me}_{6} \mathrm{TREN} \quad(\operatorname{tris}(N, N$-dimethyl-2-aminoethyl) amine), thiophene, triphenylphosphine and an $N$-heterocyclic carbene were all tried but in each case the chemical shifts of the $\mathrm{TMP}^{-}$and donor molecules were unmoved. Pyridine was also examined and found to alter the resonances (only by an approximate $0.03 \mathrm{ppm}$ downfield shift) as noted previously by Fisher and Alyea (via ${ }^{113} \mathrm{Cd}$ NMR spectroscopy), suggesting the presence of a $\mathrm{Cd}-\mathrm{N}$ interaction. We were however unable to isolate and characterize a tangible pyridine adduct of $\mathbf{2}$. It is interesting that only a sterically unencumbered $\mathrm{sp}^{2}$ Lewis donor could apparently access the metal centre suggesting that cadmium may be unable to accommodate three bulky TMP anions around it in a cadmate such as $\mathbf{1}$, thus putting a doubt in our minds about the validity of its tris-TMP formulation.

With a pure sample of $\mathrm{Cd}(\mathrm{TMP})_{2}$ to hand, we attempted to prepare the active base via a co-complexation strategy with $\mathrm{Li}$ (TMP) (using its THF solvate ${ }^{15}$ in non-polar hexane medium in an attempt to maximise the opportunity for single crystal growth). Unfortunately, only the homometallic starting materials were recovered upon recrystallisation. Undeterred, we next examined some deprotonative metallation reactions, using the well studied aromatic molecule anisole (methoxybenzene) as a test substrate. This substrate has previously been studied with $\mathbf{1}$ as well as with homometallic reagents $\mathbf{2}$ (presumably prepared in situ from LiTMP and $\mathrm{CdCl}_{2}$ ) and $\mathrm{Li}(\mathrm{TMP})$. A sample of $\mathbf{1}$ (prepared in situ according to eqn (1)) has been reported to metallate two molar equivalents of PhOMe in the ortho position in a $74 \%$ yield as quantified by electrophilic trapping with iodine, while 2 does not metallate this substrate at all and Li(TMP) gives only a miserly $9 \%$ conversion (Table 1 , entries $1-3$ ). In our study we prepared 1 using equimolar amounts of $\mathrm{Cd}(\mathrm{TMP})_{2}$ and $\mathrm{Li}$ (TMP) in THF (entry 4). After stirring this solution with two molar equivalents of anisole for two hours, quenching with iodine and aqueous work-up, the desired $o$-iodoanisole was obtained in $88 \%$ yield (as determined by integration of the methoxy resonance against a known amount of ferrocene), higher than that obtained previously when the same bimetallic base is prepared in situ via the transmetallation route described by eqn (1). To establish if either of the additives used in the in situ preparation were responsible for the diminished yield, this reaction was repeated in the respective presence of TMEDA (entry 5), two molar equivalents of $\mathrm{LiCl}$ (entry 6) and finally with both additives (entry 7).

Interestingly, the yield of $o$-iodoanisole obtained (81-89\%) appeared to be largely unaffected by the presence of $\mathrm{LiCl}$ or

Table 1 Yields of iodinated anisole using various TMP sources

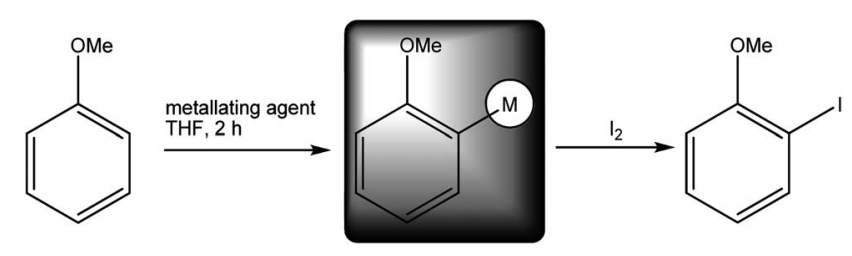

\begin{tabular}{lll}
\hline & Metallating source & Yield of $o$-iodoanisole \\
\hline 1 & $\mathrm{CdCl}_{2} \cdot \mathrm{TMEDA}+3 \mathrm{LiTMP}(\mathbf{1})$ & $74^{a}$ \\
2 & $\mathrm{Cd}(\mathrm{TMP})_{2}(\mathbf{2})$ & $0^{a}$ \\
3 & $\mathrm{LiTMP}$ & $9^{a}$ \\
4 & $\mathrm{Cd}(\mathrm{TMP})_{2}+\mathrm{LiTMP}$ & $88^{b}$ \\
5 & $\mathrm{Cd}(\mathrm{TMP})_{2}+\mathrm{LiTMP}+\mathrm{TMEDA}$ & $89^{b}$ \\
6 & $\mathrm{Cd}(\mathrm{TMP})_{2}+\mathrm{LiTMP}+2 \mathrm{LiCl}$ & $81^{b}$ \\
7 & $\mathrm{Cd}(\mathrm{TMP})_{2}+\mathrm{LiTMP}+2 \mathrm{LiCl}+\mathrm{TMEDA}$ & $85^{b}$ \\
\multirow{2}{*}{ Yields taken from ref. 13. ${ }^{b}$ Yields calculated by integrating the } \\
methoxy resonance against a standard amount of inert ferrocene.
\end{tabular}


TMEDA, intimating that these species when added separately might not play a role in the metallation reaction. The fact that using previously prepared $\mathrm{Cd}(\mathrm{TMP})_{2}$ gives a greater yield than generating it in situ is interesting and demonstrates the variations possible in chemical reactions depending on the manner in which any particular reagent is dispensed. This complication has previously been highlighted by Collum et al. in aromatic ortholithiation $^{20}$ and 1,4-addition ${ }^{21}$ reactions involving lithium diisopropylamide derived from commercial $n \mathrm{BuLi}$, where the outcome of the reaction can be influenced by a minute amount of additive (in this case $\mathrm{LiCl}$ ) its presence often unintended, in the reagent.

So as to gain a deeper understanding of the active metallating agent in solution we turned our attention to a NMR spectroscopic study of putative complex $\mathbf{1}$. Like previously published protocol, ${ }^{13 a-c}$ a $1: 3$ mixture of $\mathrm{CdCl}_{2}$ and $\mathrm{Li}(\mathrm{TMP})$ were analysed in THF using ${ }^{1} \mathrm{H}$ NMR spectroscopy. Surprisingly the spectrum displayed resonances consistent with the parent homometallic TMP species as displayed in Fig. 4.

While this solitary evidence suggests that there is no heterometallic species formed, we carried out DOSY (Diffusion Ordered SpectroscopY) NMR spectroscopy to probe this mixture further. ${ }^{22}$ DOSY NMR spectroscopy is a powerful twodimensional technique which can separate out individual components within a solution by their diffusion coefficient, which in approximate terms can be correlated to the molecular weight of a species. Provided inert samples of known molecular weight are included, the molecular weight of any 'unknown' species in the solution can be predicted. In, to the best of our knowledge, the first such DOSY study of a cadmium complex, a
$1: 3$ mixture of $\mathrm{CdCl}_{2}$ and $\mathrm{Li}(\mathrm{TMP})$ were studied in THF solution at $27^{\circ} \mathrm{C}$ with the standards tetramethylsilane (TMS), 1-phenylnaphthalene $(\mathrm{PhN})$ and 1,2,3,4-tetraphenylnaphthalene $(\mathrm{TPhN})$ present so as to obtain a calibration graph (Graph S1 in ESI $\dagger$ ). The resulting ${ }^{1} \mathrm{H}$ DOSY NMR spectrum is shown in Fig. 5.

Before even taking a quantitative analysis of the resulting data, it seems that the $\mathrm{TMP}^{-}$resonances correspond to a species with a molecular weight between those of phenylnaphthalene (204.27) and tetraphenylnaphthalene (432.55), implying that a contacted lithium TMP cadmate of formula $\mathrm{LiCd}(\mathrm{TMP})_{3}(\mathrm{MW}=540.09)$ is not the species present in solution under the conditions studied. A linear plot was subsequently obtained between $\log D$ and $\log$ FW for the inert standard $\left(r^{2}=0.9867\right.$, see Table 2 for diffusion coefficients for each of the components in solution). The robustness of the data was tested by comparing the experimentally determined formula weight $\left(\mathrm{FW}_{\mathrm{DOSY}}\right)$ of the TMP(H) byproduct (whose generation by hydrolysis cannot be suppressed in $\mathrm{d}_{8}$-THF, ${ }^{15} \mathrm{FW}_{\text {DOSY }}=136 \mathrm{~g} \mathrm{~mol}^{-1}$ ) with its actual formula weight $\left(141.25 \mathrm{~g} \mathrm{~mol}^{-1}\right)$ with a good fit being seen. The predicted formula weights of the unknown species in solution were then calculated to be $327 \mathrm{~g} \mathrm{~mol}^{-1}$ and $392 \mathrm{~g} \mathrm{~mol}^{-1}$ for the $\mathrm{Cd}-$ and $\mathrm{Li}-$ containing homometallic species respectively. The former value is depressed with respect to the expected value for $\mathrm{Cd}(\mathrm{TMP})_{2}$ $\left(\mathrm{FW}=392.90 \mathrm{~g} \mathrm{~mol}^{-1}, \mathrm{FW}_{\text {DOSY }}=83 \%\right)$ which is a common occurrence in DOSY spectroscopy when the molecule being studied has a single central atom substantially larger than its other atoms $\left[\right.$ c.f. $\mathrm{Zn}(\mathrm{TMP})_{2}$ which gives a $\mathrm{FW}_{\mathrm{DOSY}}$ of $81 \%$ of its true value]. ${ }^{23}$ The latter value is consistent with a species of formula $\mathrm{Li}(\mathrm{TMP}) \cdot 2 \mathrm{LiCl}\left[\mathrm{FW}_{\mathrm{DOSY}}=401 \mathrm{~g} \mathrm{~mol}^{-1}\right]{ }^{24}$ This

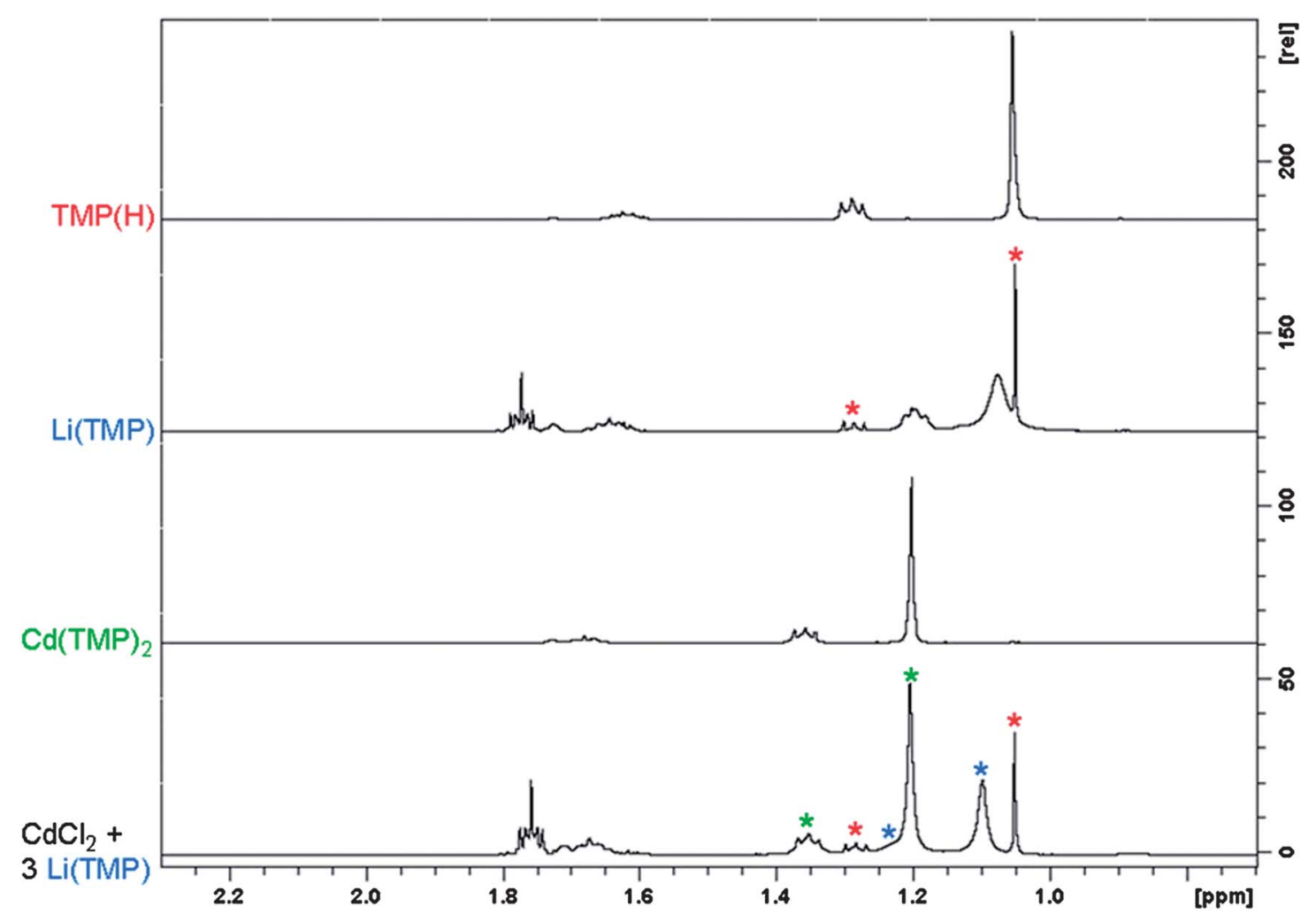

Fig. 4 Aliphatic region of ${ }^{1} \mathrm{H}$ NMR spectra of TMP(H), Li(TMP), Cd(TMP $)_{2}$ and putative base $\mathbf{1}$ in $\mathrm{d}_{8}$-THF solution at $27^{\circ} \mathrm{C}$. 


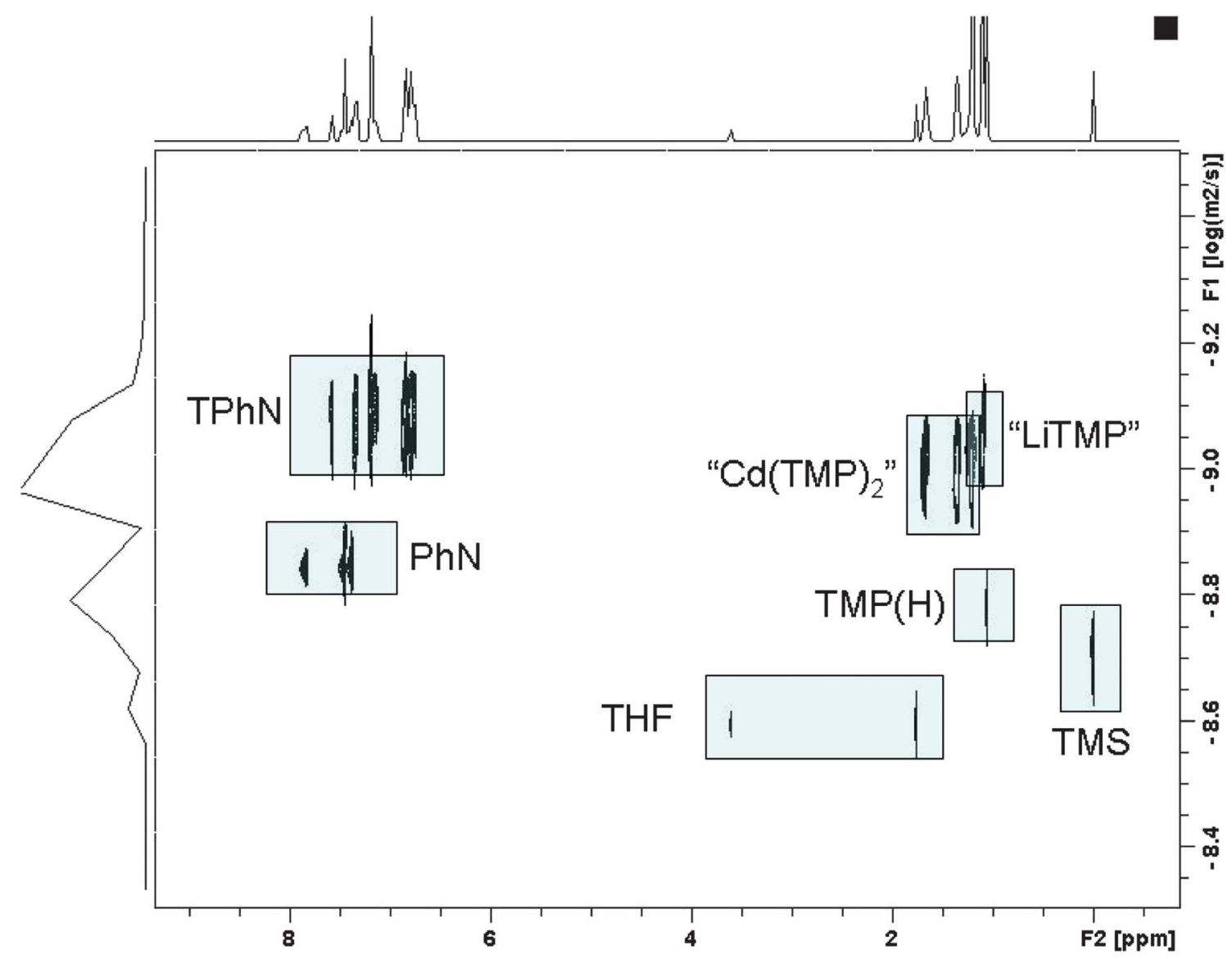

Fig. $5{ }^{1} \mathrm{H}$ DOSY NMR spectrum of $\mathrm{CdCl}_{2}+3 \mathrm{Li}(\mathrm{TMP})$ in $\mathrm{d}_{8}-\mathrm{THF}$ at $27^{\circ} \mathrm{C}$ in the presence of the inert standards tetraphenylnaphthalene (TPhN), phenylnaphthalene $(\mathrm{PhN})$ and tetramethylsilane (TMS).

evidence taken together allows us to propose an alternative outcome to the reaction (eqn (2)), whereby the transfer of TMP ligands from lithium to cadmium stops at two equivalents with the third equivalent remaining on lithium.

$$
\mathrm{CdCl}_{2}+3 \mathrm{Li}(\mathrm{TMP}) \stackrel{\mathrm{THF}}{\longrightarrow} \mathrm{Cd}(\mathrm{TMP})_{2}+\mathrm{Li}(\mathrm{TMP}) \cdot 2 \mathrm{LiCl}
$$

With this experimental evidence suggesting that $\mathrm{Cd}(\mathrm{TMP})_{2}$ and $\operatorname{Li}(\mathrm{TMP})$ co-exist independently in THF solution without interacting with one another, we considered that perhaps the metallation of an aromatic substrate $(\mathrm{ArH})$ with this mixture may rather proceed by a two-step mechanism involving lithiation with Li(TMP) (or some form of it) firstly (which is already known to metallate a substrate such as anisole, albeit it in poor yield - see Table 1 entry 3 for details) followed by

Table 2 Diffusion coefficients obtained from ${ }^{1} \mathrm{H}$ DOSY NMR experiment

\begin{tabular}{lc}
\hline Compound & $10^{-10} D\left(\mathrm{~m}^{2} \mathrm{~s}^{-1}\right)$ \\
\hline TPhN & 7.84 \\
PhN & 13.07 \\
TMS & 19.15 \\
"Cd(TMP)," & 8.55 \\
"Li(TMP)" & 9.46 \\
TMP(H) & 15.45 \\
\hline
\end{tabular}

transmetallation with $\mathrm{Cd}(\mathrm{TMP})_{2}$ to give a cadmated aromatic species (eqn (3)).

$$
x(\mathrm{Ar}) \mathrm{Li}+\mathrm{Cd}(\mathrm{TMP})_{2} \rightarrow(\mathrm{Ar})_{x} \mathrm{Cd}(\mathrm{TMP})_{2-x}+x \operatorname{Li}(\mathrm{TMP})
$$

To explore this hypothesis, we studied an authentic sample of ortho-lithiated anisole ${ }^{25}$ with pure $\mathrm{Cd}(\mathrm{TMP})_{2}$ in a $2: 1$ stoichiometry in $\mathrm{d}_{8}-\mathrm{THF}$, again via NMR spectroscopy. Interestingly, the aromatic region of the ${ }^{1} \mathrm{H}$ NMR spectrum displays four distinct resonances consistent with an ortho disubstituted aromatic species but with all the resonances shifted significantly with respect to those in the lithiated starting material (compare Fig. 6b with c).

Most indicative of a transmetallation was the presence of satellites on either side of the downfield resonance (at $7.49 \mathrm{ppm}$ ) with a coupling constant $\left({ }^{3} J_{\mathrm{CdH}}=39 \mathrm{~Hz}\right)$ and intensity (the central doublet constitutes $74 \%$ of the total intensity, the natural abundance of the NMR active nuclei of cadmium are 12.80 and $12.22 \%$ for ${ }^{111} \mathrm{Cd}$ and ${ }^{113} \mathrm{Cd}$ respectively) consistent with that expected for coupling to $\mathrm{Cd} .{ }^{26}$ Importantly, such evidence is not available when studying the lighter group 12 metal, zinc, due to its NMR inactivity. The aliphatic region also appeared different from that of the starting materials; while congested it was clear that there were now two distinct TMP methyl groups. Further support for a transmetallation reaction was gleaned from a $2 \mathrm{D}$ ${ }^{1} \mathrm{H}-{ }^{7} \mathrm{Li}$ HOESY NMR experiment (Fig. 7), which showed a cross 


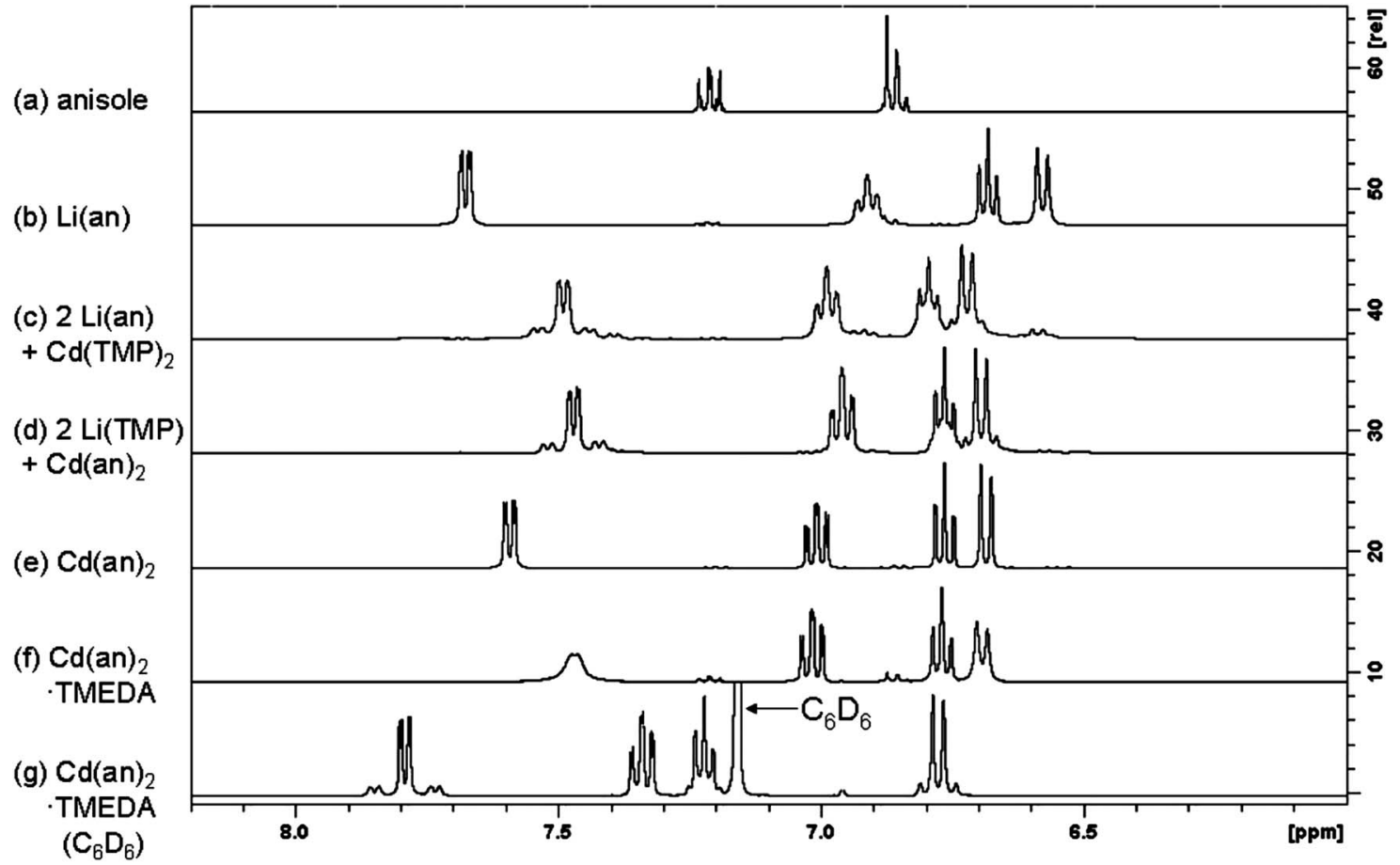

Fig. 6 Expansion of the aromatic region of ${ }^{1} \mathrm{H}$ NMR spectra of various anisole containing species $\left[\right.$ an $\left.=\left(o-\mathrm{C}_{6} \mathrm{H}_{4} \mathrm{OMe}\right)^{-}\right]$in $\mathrm{d}_{8}-\mathrm{THF}$ solution at $27^{\circ} \mathrm{C}$ (spectrum $\mathrm{g}$ obtained in $\mathrm{C}_{6} \mathrm{D}_{6}$ ).

peak consistent with a lithium-methyl (TMP) interaction. No cross peaks were witnessed for the aromatic or methoxy resonance suggesting there is no lithium-anisole fragments (for example in a heteroleptic lithium anisole/TMP cadmate) but we cannot definitively rule this out since these resonances are weaker (representing 1/12 and 1/4 of the intensities of the TMP methyl resonance respectively) and increasing the collection time did not improve the spectrum. ${ }^{27}$

To further support this hypothesis, an authentic sample of the anticipated aryl cadmium compound $\left(\mathrm{MeOC}_{6} \mathrm{H}_{4}\right)_{2} \mathrm{Cd}$ was prepared through a metathesis reaction of two molar equivalents of lithiated anisole with $\mathrm{CdCl}_{2}$ (see Fig. 6e). Cadmated bis

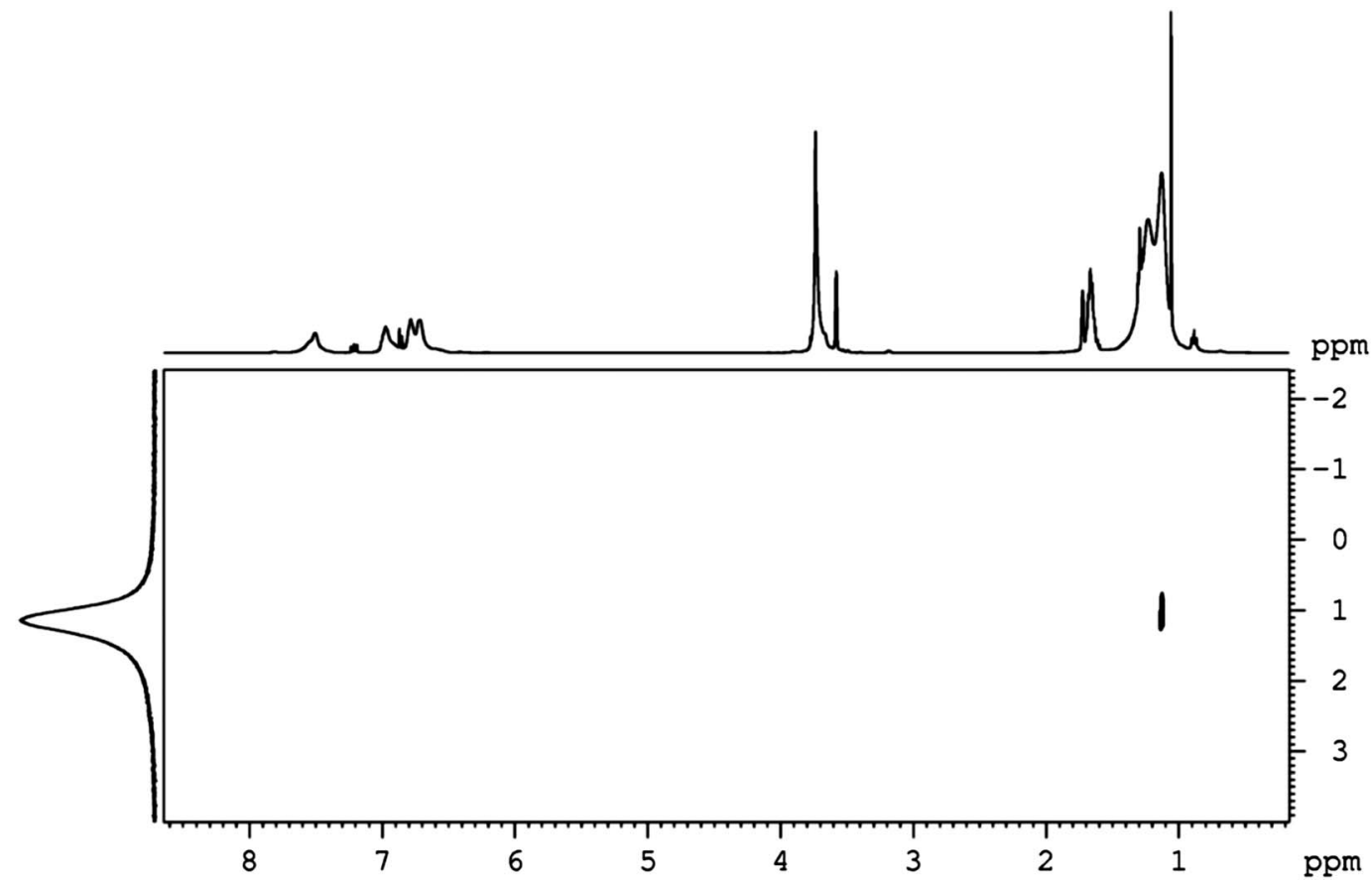

Fig. $7 \quad{ }^{1} \mathrm{H}-{ }^{7} \mathrm{Li}$ HOESY NMR spectrum of lithiated anisole $+\mathrm{Cd}(\mathrm{TMP})_{2}$ showing a lithium-TMP(methyl) interaction. 
(anisole) compounds have incidentally previously found use as synthons for the $\mathrm{C}_{6} \mathrm{H}_{4} \mathrm{OMe}^{-}$anion in various organic preparative reactions such as in the synthesis of aromatic C-nucleosides ${ }^{28}$ and antiatherosclerotic agents ${ }^{29}$ but these are invariably prepared via transmetallation from an aryl Grignard reagent with $\mathrm{CdCl}_{2}$ and used in situ without characterisation. After our transmetallation reaction, removal of the $\mathrm{LiCl}$ by-product could not be achieved by fractional crystallisation due to the near identical solubility profiles of the aryl cadmium species with $\mathrm{LiCl}$, although integration ratios from a crude ${ }^{1} \mathrm{H}$ NMR spectrum indicated an empirical formula of $\left(\mathrm{MeOC}_{6} \mathrm{H}_{4}\right)_{2} \mathrm{Cd} \cdot 2 \mathrm{THF}$. We were able to crystallise this species as its TMEDA solvated adduct (3), and obtained a low quality molecular structure confirming it as a four-coordinated (tetrahedral) cadmium species although extensive disorder over the aryl anions and the neutral bidentate donor render it useless except for establishing connectivity. Such connectivity does however give us confidence to use monomeric cadmated anisole models in our DFT calculations (vide infra).

The ${ }^{1} \mathrm{H}$ NMR spectrum of 3 in $\mathrm{d}_{8}$-THF (Fig. 6f) shows striking similarities to the aromatic region of the $\left(\mathrm{MeOC}_{6} \mathrm{H}_{4}\right) \mathrm{Li} / \mathrm{Cd}$ $(\mathrm{TMP})_{2}$ spectrum (Fig. 6c). It is of interest to note that this spectrum gives a broad resonance for the proton ortho to cadmium, with no obvious ${ }^{3} J_{\mathrm{CdH}}$ satellites. However, the same sample studied in $\mathrm{C}_{6} \mathrm{D}_{6}$ reveals such satellites with a coupling constant of $46 \mathrm{~Hz}$ (Fig. $6 \mathrm{~g}$ ). The ${ }^{3} J_{\mathrm{CdH}}$ coupling constant of 3 is intermediate between those previously reported in a series of bisalkyl cadmium complexes $(55-70 \mathrm{~Hz})^{30}$ and a series of cadmium cyclam complexes $(1.6-27.4 \mathrm{~Hz}){ }^{31}$ Directly related to the dihedral $(\mathrm{Cd}-\mathrm{C}-\mathrm{C}-\mathrm{H})$ angle, this coupling constant is greater than that predicted by Vašák in a previously reported ${ }^{3} J_{\mathrm{CdH}}$ Karplus type correlation (for a series of cadmium substituted metalloproteins) ${ }^{32}$ however, this correlation was derived in the absence of any data in the dihedral angle range of $0-20^{\circ}$ (the planar aromatic system such as in $\mathbf{3}$ dictates that two ortho substituents must have a dihedral angle of approximately $0^{\circ}$ ). Of particular further interest in this spectrum (see Fig. $\mathrm{S} 3 \dagger$ for an enlarged spectrum) was the presence of ${ }^{4} J_{\mathrm{CdH}}$ satellites (24 and $27 \mathrm{~Hz}$ for the resonances of the hydrogen atoms ortho and para to the methoxy group respectively) which are to the best of our knowledge the first such reported examples of ${ }^{4} J_{\mathrm{CdH}}$ coupling and can be considered a form of $\mathrm{W}$-coupling. ${ }^{33}$

Finally, we returned to DFT calculations to glean more information on the potential of a transmetallation process occurring between lithiated anisole and $\mathrm{Cd}(\mathrm{TMP})_{2}$. This commenced by calculating the stabilities of unsolvated $\left(\mathrm{MeOC}_{6} \mathrm{H}_{4}\right)_{2} \mathrm{Cd}$ as well as its mono and bis-THF solvated structures. These calculations confirmed that the four coordinate monomeric species $\left(\mathrm{MeOC}_{6} \mathrm{H}_{4}\right)_{2} \mathrm{Cd} \cdot 2 \mathrm{THF}$, which we previously concluded was the most likely product on the basis of our ${ }^{1} \mathrm{H}$ NMR study coupled with the preliminary solid state structure of its TMEDA solvated congener (vide supra), was the most energetically stable of the three models by 13.67 and $5.95 \mathrm{kcal} \mathrm{mol}^{-1}$ over the unsolvated and monosolvated structures respectively (see Fig. 8 for optimized model and Fig. S4 and S5 $\uparrow$ for details of unsolvated and monosolvated models).

To further test this transmetallation hypothesis, we also then calculated the energetics of the transmetallation reaction summarised in Scheme 2 (see ESI $\uparrow$ for minimum energy structures of

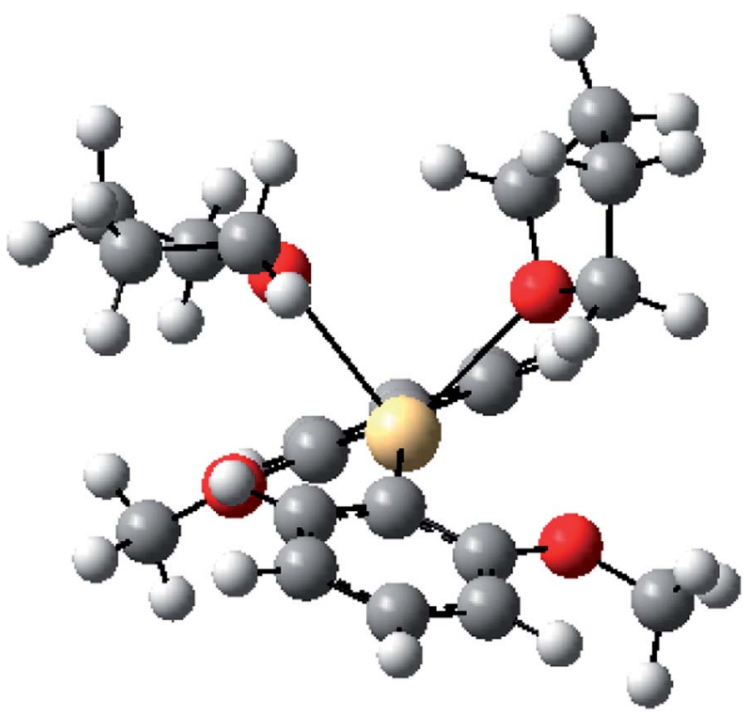

Fig. 8 Minimum energy structure of $\left(\mathrm{MeOC}_{6} \mathrm{H}_{4}\right)_{2} \mathrm{Cd} \cdot 2 \mathrm{THF}$ model (red $=$ oxygen, cream $=$ cadmium, grey $=$ carbon). Selected bond lengths (A) and angles $\left(^{\circ}\right)$ : Cd-C 2.208 and 2.203, $\mathrm{O}_{\text {Aryl }}-\mathrm{Cd} 3.070$ and 3.140, Cd-O $\mathrm{O}_{\mathrm{THF}} 2.573$ and 2.649; C-Cd-C 159.4, O-Cd-O 80.7.

molecules used in the study). We used tetrameric lithiated anisole as a starting material as this has been studied previously ${ }^{25}$ and is not deaggregated by the related cyclic ethers ethylene oxide or propylene oxide. ${ }^{34}$ Since this was found to be a highly exothermic reaction $\left(\Delta E=-35.31 \mathrm{kcal} \mathrm{mol}^{-1}\right)$ it seems to lend growing support that such a process is occurring experimentally.

With these new findings a pattern is emerging whereby the seemingly simple formation of 'ate' complexes via a cocomplexation strategy of the two parent homometallic reagent is in fact a more complicated picture which is strongly dependent on the identity of the metals, the anions and the neutral ligands employed. By employing an NMR active subordinate metal, in this case cadmium, a wealth of new information can be gleaned

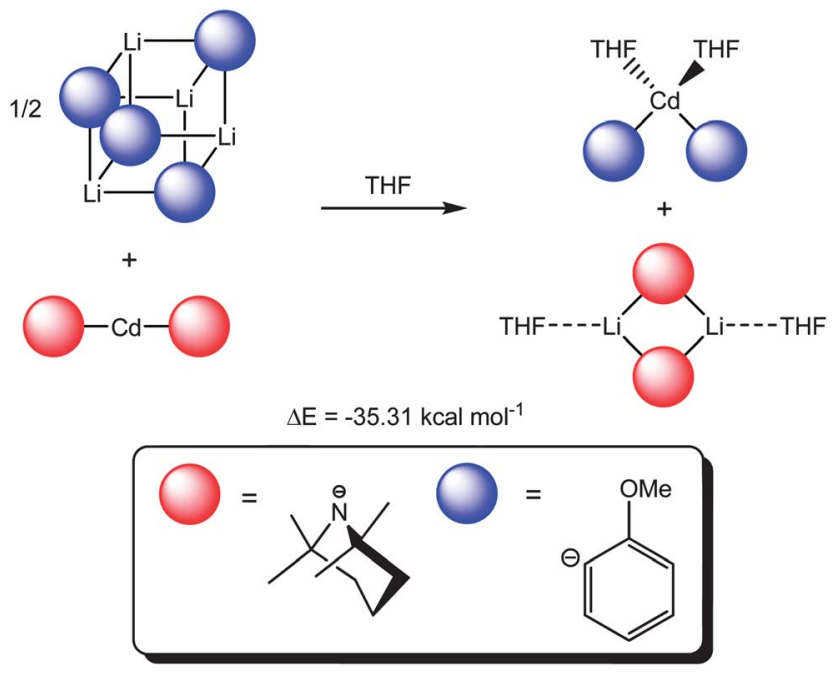

Scheme 2 Calculated transmetallation reaction of lithiated anisole and Cd(TMP $)_{2}$ in THF solution. For full geometric details of all components of this reaction see ESI. $\dagger$ 
into the processes occurring in such solution which was previously unobtainable due to the NMR silence of previously studied metals such as zinc. What is certain is that our visualisation of this chemistry is still very blurred and considerably more research is required to help us see into the black box and view its contents to enable the rational design of mixed-metallation reactions in the future.

\section{Conclusions}

Comprehensively characterized for the first time, $\mathrm{Cd}(\mathrm{TMP})_{2}$ does not appear to associate with Li(TMP) in solution to give a contacted lithium cadmate species but rather the two homometallic components remain individually intact as evidenced by DOSY NMR spectroscopy. The mixture of these two species undoubtedly results in cooperative chemistry as evidenced by the superior metallation of functionalized aromatic substrates when working in tandem as compared to working individually. Through a variety of NMR spectroscopy experiments, supported by theoretical calculations, we have gathered direct spectroscopic evidence that suggests that rather than a synergic metallation (cadmation) of the substrate occurring, a two-step process involving first ortho-lithiation, followed by a transmetallation to the more carbophilic cadmium takes place. This result demands a comprehensive study of other mixed-metal TMP reagents in their own right.

\section{Acknowledgements}

We thank the UK Engineering and Physical Science Research Council (award no. EP/F063733/1) and the Royal Society/ Wolfson Foundation (research merit award to R.E.M.) for funding this research and Craig Irving for expert help with NMR spectroscopy.

\section{Notes and references}

$1 \mathrm{M}$. Schlosser, Organometallics in Synthesis: A Manual, Wiley, Chichester, 2nd edn, 2002.

2 J. Clayden, Organolithiums: Selectivity for Synthesis, Elsevier, Oxford, 1st edn, 2002.

3 P. Knochel, A. Krasovskiy and I. Sapountzis, in Handbook of Functionalized Organometallics, ed. P. Knochel, Wiley-VCH, Weinheim, 2005, pp. 109-172.

4 P. Knochel, H. Leuser, L. -Z. Gong, S. Perrone and F. F. Kneisel, in Handbook of Functionalized Organometallics, ed. P. Knochel, WileyVCH, Weinheim, 2005, pp. 251-346.

5 (a) R. E. Mulvey, F. Mongin, M. Uchiyama and Y. Kondo, Angew. Chem., Int. Ed., 2007, 46, 3802-3824; (b) For a review of AMMM see: R. E. Mulvey, Acc. Chem. Res., 2009, 42, 743-755; (c) B. Haag, M. Mosrin, H. Ila, V. Malakhov and P. Knochel, Angew. Chem., Int. Ed., 2011, 50, 9794-9824.

6 R. E. Mulvey, Organometallics, 2006, 25, 1060-1075.

7 R. E. Mulvey, D. R. Armstrong, B. Conway, E. Crosbie, A. R. Kennedy and S. D. Robertson, Inorg. Chem., 2011, 50, 12241-12251.

8 V. L. Blair, W. Clegg, R. E. Mulvey and L. Russo, Inorg. Chem., 2009, 48, 8863-8870, and references cited therein.

9 (a) P. Alborés, L. M. Carella, W. Clegg, P. García-Álvarez, A. R. Kennedy, J. Klett, R. E. Mulvey, E. Rentschler and L. Russo, Angew. Chem., Int. Ed., 2009, 48, 3317-3321; (b) E. Nagaradja, F. Chevallier, T. Roisnel, V. Jouikov and F. Mongin, Tetrahedron, 2012, 68, 3063-3073.

10 G. Dayaker, F. Chevallier, P. C. Gros and F. Mongin, Tetrahedron, 2010, 66, 8904-8910.
11 (a) T. T. Nguyen, F. Chevallier, V. Jouikov and F. Mongin, Tetrahedron Lett., 2009, 50, 6787-6790; (b) T. T. Nguyen, N. Marquise, F. Chevallier and F. Mongin, Chem.-Eur. J., 2011, 17, 10405-10416.

12 (a) G. Wittig, F. J. Meyer and G. Lange, Liebigs Ann., 1951, 571, 167201; (b) For an NMR study of $\mathrm{LiCdEt}_{3}$ see: S. Toppet, G. Slinckx and G. Smets, J. Organomet. Chem., 1967, 9, 205-213.

13 (a) J.-M. L'Helgoual'ch, G. Bentabed-Ababsa, F. Chevallier, M. Yonehara, M. Uchiyama, A. Derdour and F. Mongin, Chem. Commun., 2008, 5375-5377; (b) K. Snégaroff, J.-M. L’Helgoual'ch, G. Bentabed-Ababsa, T. T. Nguyen, F. Chevallier, M. Yonehara, M. Uchiyama, A. Derdour and F. Mongin, Chem.-Eur. J., 2009, 15, 10280-10290; (c) K. Snégaroff, S. Komagawa, M. Yonehara, F. Chevallier, P. C. Gros, M. Uchiyama and F. Mongin, J. Org. Chem., 2010, 75, 3117-3120; (d) G. Bentabed-Ababsa, S. C. S. Ely, S. Hesse, E. Nassar, F. Chevallier, T. T. Nguyen, A. Derdour and F. Mongin, J. Org. Chem., 2010, 75, 839-847; (e) G. Dayaker, A. Sreeshailam, F. Chevallier, T. Roisnel, P. Radha Krishna and F. Mongin, Chem. Commun., 2010, 46, 2862-2864; (f) A. Sreeshailam, G. Dayaker, F. Chevallier, T. Roisnel, P. Radha Krishna and F. Mongin, Eur. J. Org. Chem., 2011, 3715-3718; $(\mathrm{g})$ K. Snégaroff, T. T. Nguyen, N. Marquise, Y. S. Halauko, P. J. Harford, T. Roisnel, V. E. Matulis, O. A. Ivashkevich, F. Chevallier, A. E. H. Wheatley, P. C. Gros and F. Mongin, Chem.-Eur. J., 2011, 17, 13284-13297.

14 (a) M. F. Lappert, M. J. Slade, A. Singh, J. L. Atwood, R. D. Rogers and R. Shakir, J. Am. Chem. Soc., 1983, 105, 302-304; (b) P. G. Williard and Q.-Y. Liu, J. Am. Chem. Soc., 1993, 115, 33803381; (c) D. R. Armstrong, A. R. Kennedy, R. E. Mulvey and S. D. Robertson, Chem.-Eur. J., 2011, 17, 8820-8831.

15 D. R. Armstrong, P. García-Álvarez, A. R. Kennedy, R. E. Mulvey and S. D. Robertson, Chem.-Eur. J., 2011, 17, 6725-6730.

16 (a) K. J. Fisher and E. C. Alyea, Polyhedron, 1984, 3, 509-512; (b) E. C. Alyea and K. J. Fisher, Polyhedron, 1986, 5, 695-701.

17 W. S. Rees Jr, O. Just, H. Schumann and R. Weimann, Polyhedron, 1998, 17, 1001-1004.

18 For the solid state structure of (1,3,6,8-tetra-tert-butylcarbazol-9yl) ${ }_{2}$ Cd see: A. J. Blake, W. Lewis, J. McMaster, R. S. Moorhouse, G. J. Moxey and D. L. Kays, Dalton Trans., 2011, 40, 1641-1645.

19 M. Karplus, J. Am. Chem. Soc., 1963, 85, 2870-2871.

20 L. Gupta, A. C. Hoepker, K. J. Singh and D. B. Collum, J. Org. Chem., 2009, 74, 2231-2233.

21 Y. Ma, A. C. Hoepker, L. Gupta, M. F. Faggin and D. B. Collum, J. Am. Chem. Soc., 2010, 132, 15610-15623.

22 D. Li, I. Keresztes, R. Hopson and P. G. Williard, Acc. Chem. Res., 2009, 42, 270-280.

23 To confirm that the formula weight of 2 predicted by DOSY NMR spectroscopy is indeed lower than its true value it was also studied in this way and gave a $\mathrm{FW}_{\text {DOSY }}$ of $302 \mathrm{~g} \mathrm{~mol}^{-1}$. See ESI for full details. $\dagger$.

24 P. García-Álvarez, R. E. Mulvey and J. A. Parkinson, Angew. Chem., Int. Ed., 2011, 50, 9668-9671.

25 S. Harder, J. Boersma, L. Brandsma, G. P. M. van Mier and J. A. Kanters, J. Organomet. Chem., 1989, 364, 1-15.

26 (a) A. D. Cardin, P. D. Ellis, J. D. Odom and J. W. Howard Jr, J. Am. Chem. Soc., 1975, 97, 1672-1679; (b) P. D. Ellis, Science, 1983, 221, 1141-1146.

27 The lithiated anisole/Cd(TMP $)_{2}$ sample in THF visibly degrades over a few hours with what appears to be cadmium metal being extruded, with resonances of free anisole being evident in the ${ }^{1} \mathrm{H}$ spectrum after $4 \mathrm{~h}$. This could not be circumvented either via cooling the sample or applying the most rigorous of air-sensitive techniques and using a sealed Young's NMR tube.

28 N. C. Chaudhuri and E. T. Kool, Tetrahedron Lett., 1995, 36, 1795-1798.

29 Y. Eguchi, Y. Sato, S. Sekizaki and M. Ishikawa, Chem. Pharm. Bull., 1991, 39, 2009-2015.

30 C. J. Turner and R. F. M. White, J. Magn. Reson., 1977, 26, 1-5.

31 X. Liang, J. A. Parkinson, S. Parsons, M. Weishäupl and P. J. Sadler, Inorg. Chem., 2002, 41, 4539-4547.

32 O. Zerbe, D. L. Pountney, W. von Philipsborn and M. Vašák, J. Am. Chem. Soc., 1994, 116, 377-378.

33 D. H. Williams and I. Fleming, Spectroscopic Methods in Organic Chemistry, McGraw-Hill, Maidenhead, 5th edn, 1995.

34 S. Harder, J. Boersma, L. Brandsma, J. A. Kanters, A. J. M. Duisenberg and J. H. van Lenthe, Organometallics, 1990, 9, 511-516. 